\title{
MicroscopyPioneers \\ Pioneers in Optics: Christiaan Huygens
}

\section{Eric Clark}

From the website Molecular Expressions created by the late Michael Davidson and now maintained by Eric Clark, National Magnetic Field Laboratory, Florida State University, Tallahassee, FL 32306

eclark@magnet.fsu.edu

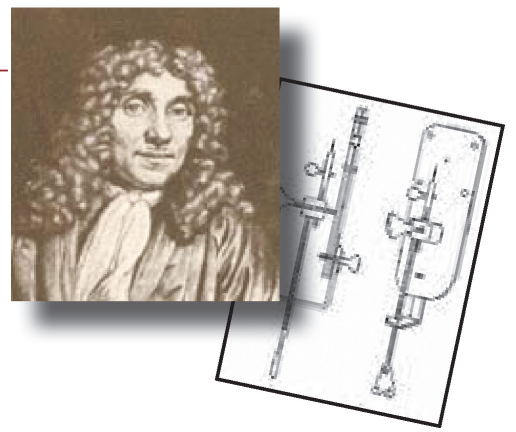

\section{Christiaan Huygens \\ (1629-1695)}

Christiaan Huygens was a brilliant Dutch mathematician, physicist, and astronomer who lived during the seventeenth century, a period sometimes referred to as the Scientific Revolution. Huygens, a highly gifted theoretical and experimental scientist, is best known for his work on the theories of centrifugal force, the wave theory of light, and the pendulum clock.

At an early age, Huygens began

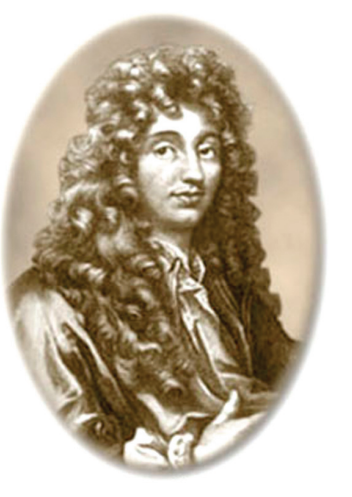
work in advanced mathematics by attempting to disprove several theories established by the ancient Greeks in simple geometry. He was also very interested in astronomy and telescopes and spent a considerable amount of time devising methods to improve both the optical and mechanical performance of the telescope. His achievements in astronomy were reported in his 1659 book entitled Systema Saturnium in which he noted his discovery of the rings encircling the planet Saturn as well as his observations about the moon, the planets, and the Orion nebula.

Huygens's keen interest in astronomy probably led to his efforts in the measurement of time and other matters relating to mechanical physics. He was heavily involved in a seventeenth-century controversy with Vincenzo Viviani as to the exact inventor of the pendulum clock, which he presented as an accomplishment of Dutch Science in his 1673 book Horologium Oscillatorium. This work may well have been one of Huygens's finest efforts because he also suggested important principles of gravity in a vacuum, as well as many aspects of classical physics including centrifugal force.

During the middle seventeenth century, Huygens wrote a small treatise on the calculus of probabilities based on the theories of Pascal and Fermat and spent several years in England. His reputation as a scholar and scientist were becoming world renowned at this point, and he was offered a pension by French King Louis XIV to relocate to Paris. In France, Huygens's work on timepieces progressed to the point of the inclusion of a balance spring to increase reliability and accuracy. The first watch using this principle was finished in 1675, whereupon it was promptly presented to his sponsor, King Louis XIV.

In 1681, Huygens returned to Holland where he began to construct optical lenses with extremely large focal lengths, which were eventually presented to the Royal Society of London, where they remain today. Continuing along this line of work, Huygens perfected his skills in lens grinding and subsequently invented the achromatic eyepiece that bears his name and is still in widespread use today.

Huygens left Holland in 1689, and ventured to London where he became acquainted with Sir Isaac Newton and began to study Newton's theories on classical physics. Although it seems Huygens was duly impressed with Newton's work, he was still very skeptical about any theory that did not explain gravitation by mechanical means.

In 1690 Huygens returned to Holland where he published a book started in 1687 on the physics of light entitled Traité de la Lumière, in which he suggested a theory to explain the wave-like nature of light. Huygens was unconvinced by the particle theory of light advanced by Newton, primarily because he thought the rapid speed of light would only be possible if light were composed of waves. He suggested that light waves traveled on an invisible "ether" that filled the void throughout air and space. In his famous "Huygens' Principle," he suggested that each point in a light wave could be explained by miniature wavelets that combined to form a wavefront. Huygens's theories neatly explained the laws of refraction, diffraction, interference, and reflection, and he went on to make major advances in the theories concerning the phenomena of double refraction (birefringence) and polarization of light.

Huygens's work in the fields of mathematics and physics led to significant steps forward in the advancement of science, particularly the fields of optics, astronomy, and mechanical physics.

Editor's Note: See the original reference to Huygens's essay in the Pioneers in Optics website https://micro.magnet. fsu.edu/optics/timeline/people/huygens.html, which includes an interactive Java tutorial, designed to illustrate the reflection and refraction of light according to the multiple wavelet concept. 


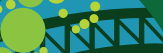

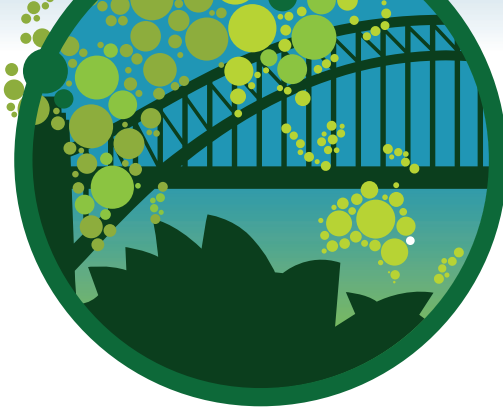

19TH INTERNATIONAL MICROSCOPY CONGRESS
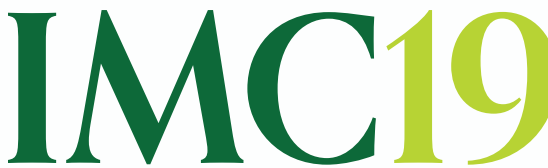

9-14 September 2018

International Convention Centre, Sydney
Registration \& Abstract Submission Now Open
ARGYLE DIAMOND PARTNER

ThermoFisher $S C I E N T$ I I C
OPAL PARTNERS JEDL $O$ ZINXS
GOLD

PARTNERS

$G \underset{\text { Inspire the Next }}{\text { HITACHI }}$
BRONZE PARTNERS

BRURER OXFORD

NanoMEGAS
MEDIA

PARTNER

Microscopy
OFFICIAL CONGRESS SPONSOR AIRLINE

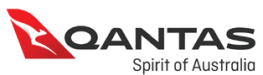

\section{WHY ATTEND IMC19?}

- Keep up to date with the latest advancements and developments in microscopy and visit our interactive trade exhibition

- Be a part of an outstanding scientific program led by world-renowned plenary speakers including Dr Misty Jenkins and Professor Dan Shechtman
- Network and share experiences and ideas with over 2000 colleagues and peers from across the globe

- IMC19 will be more interactive and engaging than ever before featuring the latest in digital poster technology accessible from onsite kiosks or your own hand held smart device

\section{AN EXCITING OPPORTUNITY FOR YOUNG SCIENTISTS}

Formerly known as the IFSM School, the IFSM Young Scientists Assembly is being organised exclusively for IFSM Young Scientists and will take place on Saturday 8 September 2018.

This program is open to all early career researchers who completed their Ph.D. within five years from the date of the Congress.

Apply today at imc19.com

\section{KEY DATES}

Abstract Submission Deadline 1 February 2018

Early Bird Registration Closes 10 May 2018

Author Registration Deadline 10 May 2018

Download Program Preview at imc19.com

\section{DISCOUNT QANTAS FLIGHTS FOR IMC19 DELEGATES}

Qantas is delighted to be the major airline sponsor for IMC19. Qantas, in conjunction with our partner airlines, are offering registered delegates and travel partner's special discounted airfares which are easily booked online at imc19.com

Qantas is Australia's largest domestic and international airline and is widely regarded as the world's leading long-distance airline. With a reputation for excellence in safety, operational reliability, and world class customer service; Qantas offers a truly global network proposition for delegates travelling to Sydney for IMC19.

\section{IMC19 SPONSORS \& EXHIBITORS}

Position your brand at the event where the global leaders in microscopy meet. For enquiries, contact Drew Whait for more information.

Email: sponsorship@arinex.com.au Phone: +61292650700

Register at our Early Bird rate and submit your abstract today at imc19.com

Find us on Facebook: IMC (1I) Join us on Instagram:

CONGRESS HOSTS
Follow us on Twitter: @IMC19Sydney 